\title{
Avaliação da variabilidade pluviométrica na bacia hidrográfica do Rio Paraíba no Estado da Paraíba
}

O Estado da Paraíba, em maior parte, está localizado na região semiárida do Brasil, possuindo um número significativo de bacias hidrográficas com características hidrogeologicamente distintas, proporcionando dificuldades econômicas e sociais recorrentes. Deste modo, o Estado da Paraíba se destaca como um do NEB que mais sofre uma variabilidade espaço-temporal das chuvas que interfere na biodiversidade da região. A área de estudo da presente pesquisa é a Bacia Hidrográfica do Rio Paraíba, no estado da Paraíba possuindo uma área de $20.071,83 \mathrm{~km} 2$ e fazendo fronteiras com o Estado de Pernambuco a Oeste e a Sul com a Bacia do Rio Gramame. Os dados pluviométricos mensais da Superintendência do Desenvolvimento do Nordeste (SUDENE), Instituto Nacional de Meteorologia (INMET) e Agência Executiva de Gestão das Águas da Paraíba (AESA), para composição da variabilidade espaço-temporal da precipitação da BHRPB. Logo, o mapeamento foi realizado utilizando os softwares Qgiz e do Golden Software Surfer. De acordo com a série histórica, foi possível evidenciar dois períodos distintos, com seis meses secos e chuvosos. O período de 1980 a 2019 a precipitação pluviométrica temporal anual apresentou 26 anos abaixo da média, destacando o ano de 1998 como o pico mínimo de $27,9 \mathrm{~mm}$ e 14 acima da média, sendo 2011 apresentando o valor máximo de 95,6 mm.

\section{Evaluation of pluviometric variability in the Paraiba hydrographic Basin, in the State of Paraiba}

\begin{abstract}
The State of Paraíba, for the most part, is located in the semi-arid region of Brazil, having a significant number of hydrographic basins with hydrogeologically distinct characteristics, providing recurrent economic and social difficulties. Thus, the State of Paraíba stands out as one of the NEB that most suffers a spatio-temporal variability of rainfall that interferes with the region's biodiversity. The study area of this research is the Paraiba River Hydrographic Basin, in the state of Paraiba, with an area of 20,071.83 km2 and bordering the State of Pernambuco to the West and to the South with the Rio Gramame Basin. Monthly rainfall data from the Northeast Development Superintendence (SUDENE), National Meteorological Institute (INMET) and Paraiba Water Management Executive Agency (AESA), to compose the spatio-temporal variability of BHRPB precipitation. Therefore, the mapping was performed using the software Qgiz and Golden Software Surfer. According to the historical series, it was possible to show two distinct periods, with six dry and rainy months. The period from 1980 to 2019 the annual temporal rainfall showed 26 years below the average, highlighting the year 1998 as the minimum peak of $27.9 \mathrm{~mm}$ and 14 above the average, with 2011 having the maximum value of $95.6 \mathrm{~mm}$.
\end{abstract}

Keywords: Water resources; Rainy and dry periods; Space-time.

Topic: Meteorologia, Climatologia e Mudanças Climáticas

Reviewed anonymously in the process of blind peer.
Received: 08/06/2021

Approved: 24/06/2021
Maxsuel Bezerra do Nascimento (iD) Universidade Estadual da Paraíba, Brasil http://lattes.cnpq.br/7100621157794567 http://orcid.org/0000-0001-6381-2688 maxsuel10gba@hotmail.com

José Ludemario da Silva Medeiros (D) Universidade Estadual da Paraíba, Brasil http://lattes.cnpq.br/4084311510300833 http://orcid.org/0000-0002-7523-9601 joseludemariomedeiros@gmail.com

Tássio Jordan Rodrigues Dantas da Silva (in Universidade Estadual da Paraíba, Brasil http://lattes.cnpq.br/1991160864996557 http://orcid.org/0000-0002-1708-5472 tassiojordan@hotmail.com

\section{Janaina Aparecida Cezário (iD} Universidade Estadual da Paraíba, Brasil Universidade Estadual da Paraíba, Brasil
http://lattes.cnpq.br/2080075497375535 http://orcid.org/0000-0002-9866-4168 ja nayna2@yahoo.com.br

Francisco Auriberto Ferreira Marques Junior (iD Universidade Estadual da Paraíba, Brasil http://lattes.cnpq.br/3276460952255224 http://orcid.org/0000-0002-5989-7719 auribertofmj@gmail.com

Gustavo Fernando Santos (iD)

Universidade Estadual da Paraíba, Brasil http://lattes.cnpq.br/8537650313113840 http://orcid.org/0000-0003-3632-3824 gustavofernandosantos13@gmail.com

\begin{tabular}{|l|} 
Jéssica Mendes da Silva \\
Universidade Estadual da Paraíba, Brasil \\
http://lattes.cnpq.br/8714594769870537 \\
jessykasilva592@gmail.com \\
Lincoln Eloi de Araújo (1) \\
Universidade Federal da Paraíba, Brasil \\
http://lattes.cnpq.br/5800585621913283 \\
http://orcid.org/0000-0002-1374-3722 \\
lincolneloi@yahoo.com.br \\
William de Paiva (1) \\
Universidade Estadual da Paraíba, Brasil \\
http:///attes.cnpq.br/2612977983185686 \\
http://orcid.org/0000-0003-0220-1247 \\
wpaiva461@gmail.com
\end{tabular}

Laércio Leal dos Santos (DD Universidade Estadual da Paraíba, Brasil http://lattes.cnpq.br/6344196123061264 http://orcid.org/0000-0002-8175-4378 laercioeng@yahoo.com.b
Referencing this:

NASCIMENTO, M. B.; MEDEIROS, J. L. S.; SILVA, T. J. R. D.; CEZARIO, J. A.; MARQUES JUNIOR, F. A. F.; SANTOS, G. F.; SILVA, J. M.; ARAÚJO, L. E.; PAIVA, W.; SANTOS, L. L.. Avaliação da variabilidade pluviométrica na bacia hidrográfica do Rio Paraíba no Estado da Paraíba. Revista Ibero Americana de Ciências Ambientais, v.12, n.6, p.223-232, 2021. DOI: http://doi.org/10.6008/CBPC2179-6858.2021.006.0019 


\section{INTRODUÇÃO}

Os eventos extremos de precipitação pluviométrica são investigados por parte da comunidade científica internacional devido aos prejuízos socioeconômicos causados pelo excesso ou escassez de chuvas em diversas regiões do mundo (FLATO et al., 2017).

De acordo com Oliveira et al. (2020) um dos grandes desafios é compreender a dinâmica das chuvas sobre uma determinada área, assim como os modos de variabilidades que influenciam as precipitações tornase um fator a ser considerado nas tomadas de decisões que envolvem essas áreas.

Compreender o clima urbano é fundamental, já que afeta diretamente as condições de vida da sociedade, visto que esse vem sendo alterado em função da própria dinâmica das cidades, com a crescente impermeabilização dos solos, a fragmentação ou eliminação da cobertura vegetal, os efluentes emitidos, a poluição do ar, o próprio desenho urbano, o que causam impactos climáticos locais (FERREIRA et al., 2019).

Deste modo, o Nordeste Brasileiro (NEB) é uma das regiões mais problemáticas no que se refere à disponibilidade de água, destacando-se ainda, pelo seu clima quente e úmido. Essa região conta com uma grande área semiárida, que corresponde a $53 \%$ do território nordestino, onde se destaca que as chuvas são bastante escassas e irregulares (FERREIRA et al., 2018).

Assim, o Estado da Paraíba, em maior parte, está localizado na região semiárida do Brasil, possuindo um número significativo de bacias hidrográficas com características hidrogeologicamente distintas, proporcionando dificuldades econômicas e sociais recorrentes, com danos ambientais negativos relacionados principalmente a poluição e contaminação da água.

O Estado da Paraíba se destaca como um do NEB que mais sofre uma variabilidade espaço-temporal das chuvas que interfere na biodiversidade da região. Logo, a Paraíba proporciona uma das maiores variabilidades espaço-temporal das chuvas anuais, visto que a região do estado conhecida como Cariri e Curimataú apresentam um baixo índice pluviométrico de 300 a 500 milímetros (mm), no Sertão e Alto Sertão uma precipitação em torno de 700 a 900 mm, no Brejo e Agreste, precipitações que variam de 700 a 1.200 mm e no Litoral apresenta precipitação alternando entre 1.200 a 1.600 mm (ARAÚJO, 2003; FRANCISCO et al., 2015).

Dentre tantas variáveis climáticas, a precipitação pluviométrica é aquela que apresenta um impacto positivo ou negativo para sociedade, já que a grande maioria das atividades econômicas, sobretudo a agrícola, são afetadas a longo prazo por tal variação, levando a aumento significativo de eventos extremos de secas e chuvosos (SIQUEIRA et al., 2017).

Além disso, a precipitação no Estado da Paraíba depende de um conjunto de vários sistemas meteorológicos tais como: Zona de Convergência Intertropical (ZCIT), Vórtices Ciclônicos de Ar Superior (VCAS), Zona de Convergência do Atlântico Sul (ZCAS), e os Distúrbios de Leste, todos esses sistemas podem ser alterados através de uma certa irregularidade atmosférica (ARAÚJO et al., 2008; PALHARINI et al., 2017).

Nascimento et al. (2019), afirmam que esses níveis de precipitação ocorrem em maior intensidade no litoral e agreste por conta do oceano Atlântico, já o sertão recebe uma boa quantidade devido a ZCIT que 
fornece chuva para essa localidade, e o Cariri e Curimataú a precipitação é menor devido ao Planalto da Borborema que serve de barreira inibindo as chuvas que vem do oceano Atlântico cheguem com tanta intensidade nessa região.

Deste modo, o objetivo principal deste trabalho é avaliar a variabilidade pluviométrica da Bacia Hidrográfica do Rio Paraíba no Estado da Paraíba, através da análise espaço-temporal mensal e anual da sua precipitação, identificando-se assim os períodos secos e chuvosos da área estudada.

\section{MATERIAIS E MÉTODOS}

\section{Localização da área de estudo}

A área de estudo da presente pesquisa é a Bacia Hidrográfica do Rio Paraíba (BHRPB), apresentado na Figura 1, localizada no Estado da Paraíba que de acordo com o Instituto Brasileiro de Geografia e Estatística (IBGE) está entre as latitudes 6051'31" e 826'21" Sul e longitudes 3448'35" e 372'15" Oeste, possuindo uma área de 20.071,83 km2 e fazendo fronteiras com o Estado de Pernambuco a Oeste e a Sul com a Bacia do Rio Gramame, com o Oceano Atlântico a Leste e com as Bacias do Espinharas, Seridó, Jacu, Curimataú, Mamanguape e Miriri ao Norte.

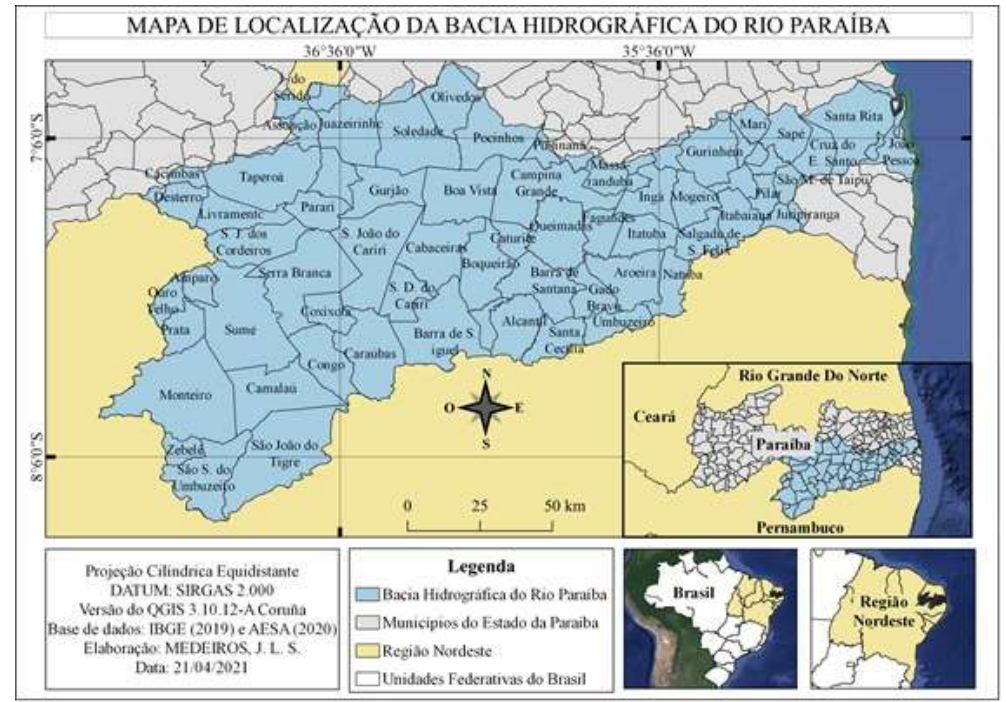

Figura 1: Mapa de Localização da Bacia Hidrográfica do Rio Paraíba, com relação ao Estado da Paraíba e ao Brasil.

A BHRPB é composta pelas regiões hidrográficas do Alto, Médio e Baixo Paraíba e na Sub-bacia do Rio Taperoá, havendo distinções entre elas tanto nas características naturais, quanto nas socioeconômicas. Além disso, é a segunda maior do Estado, pois de acordo com o IBGE 2021 abrange 38\% do seu território, com uma população estimada de 1.828.178 que correspondem a 52\% da população total da Paraíba.

Deste modo, em termos populacionais pode se caracterizar que a região do Baixo Curso do rio Paraíba é a mais habitada, ou seja, tal fato Ihe proporciona um alto grau de urbanização. Em seguida pelo Médio Curso do rio Paraíba, e juntas o Alto Curso do rio Paraíba e a Sub-Bacia do Taperoá como as menores em termos populacionais.

Portanto, sendo a principal bacia hidrográfica de domínio estadual, estão incluídos os municípios de 
João Pessoa e Campina Grande, que são considerados os dois maiores centros urbanos do Estado, além de outros 83 municípios que estão inseridos totalmente ou parcialmente em seus domínios.

\section{Dados pluviométricos}

No desenvolvimento desta pesquisa foram utilizados dados pluviométricos mensais da Superintendência do Desenvolvimento do Nordeste (SUDENE), Instituto Nacional de Meteorologia (INMET) e Agência Executiva de Gestão das Águas da Paraíba (AESA), para composição da variabilidade espaçotemporal da precipitação da BHRPB.

Inicialmente, com os dados de precipitação disponibilizados no período de 1980 a 2019 foram gerados gráficos (no Excel 2019) da variabilidade temporal da pluviometria no intuito de analisar a série histórica, onde através desses dados foi possível entender o comportamento da variável na BHRPB em estudo, demonstrando assim a dinâmica climática.

Posteriormente, foram elaborados mapas e/ou figuras da variabilidade espacial da precipitação na BHRPB. Vale destacar que os dados pluviométricos obtidos possuem falhas de alguns meses e de até anos em alguns postos, e que foram utilizados métodos estatísticos de ponderação regional, para o preenchimento de falhas para completar as lacunas e prosseguir o andamento da pesquisa.

Neste sentido, foram utilizados os softwares Qgiz (versão 3. 16. 0) e do Golden Software Surfer (versão 16.0), ambos com características distintas, porem em conjunto serviu para dá mais credibilidade na pesquisa, de maneira que as figuras fossem demostradas com os objetivos propostos.

Além disso, no mapeamento foi utilizado o método de Krigagem ordinária, para gerar as figuras de espacialização em todas as variáveis físicas (Temperatura, URA e Precipitação), proposta na pesquisa. semivariograma é a parte central dos estudos geoestatísticos, sendo capaz de descrever tanto qualitativa quanto quantitativamente a variação espacial, além de ser o ponto chave na determinação do preditor geoestatístico-krigagem. Portanto, vale destacar que o número de postos meteorológicos encontrados para a pluviosidade foi de 81 pontos.

\section{Preenchimento de falhas}

O método de preenchimento de falhas utilizado no estudo, foi o da ponderação regional (Equação 1), para estimar os valores que faltam e assim dar mais objetividade aos resultados da pesquisa.

A escolha dos postos a serem utilizados no método de ponderação regional deve levar em consideração um intervalo mínimo de série (usualmente 30 anos), e estar em uma região climatológica semelhante.

$$
\mathrm{PX}=\frac{1}{n-1} *\left(\frac{\mathrm{PA}}{\mathrm{PAm}}+\frac{\mathrm{PB}}{\mathrm{PBm}}+\frac{\mathrm{PC}}{\mathrm{PCm}}+n\right) * \mathrm{PXm} \quad \text { (Equação 1) }
$$

Onde PXm, PAm, PBm e PCm são as precipitações médias nos postos $\mathrm{X}, \mathrm{A}, \mathrm{B}$ e $\mathrm{C}$, respectivamente de acordo com a série de dados disponibilizadas; $P X$, é a precipitação no posto $X$ a determinar; $P A, P B$ e $P C$ são as precipitações nos postos $\mathrm{A}, \mathrm{B}$ e $\mathrm{C}$ existentes, respectivamente, no intervalo de tempo referente àquele da precipitação no posto $\mathrm{X}$ a determinar.

Este método consiste em estimar a precipitação ocorrida no posto pluviométrico com falha 
considerando-a adequada às precipitações em postos vizinhos, sendo o fator de proporcionalidade a função da precipitação média nestes postos, levando em consideração a precipitação média no próprio posto com falha. Além disso, é empregado elegendo ao menos três postos vizinhos àquele com ausência de dados, os quais necessitam estar localizados em regiões climáticas semelhante ao posto com falha.

Após o procedimento de preenchimento de falhas, foi utilizado o método da Dupla Massa (Figura 2), desenvolvido pelo Geological Survey (EUA), a principal finalidade do método é identificar se ocorreram mudanças no comportamento da precipitação ao longo do tempo, ou mesmo no local de observação para comprovar que os dados estão seguindo o modelo estatístico previsto de forma linear.

Logo, se os pontos de um determinado gráfico se alinharem em uma reta aproximada, isso indica uma proporcionalidade entre os dados dos dois postos em questão. Assim sendo, o simples fato de se ver o R2 próximo a 1, não é suficiente para analisar o erro, porem já determina que o coeficiente de regressão se aproxima do resultado previsto.

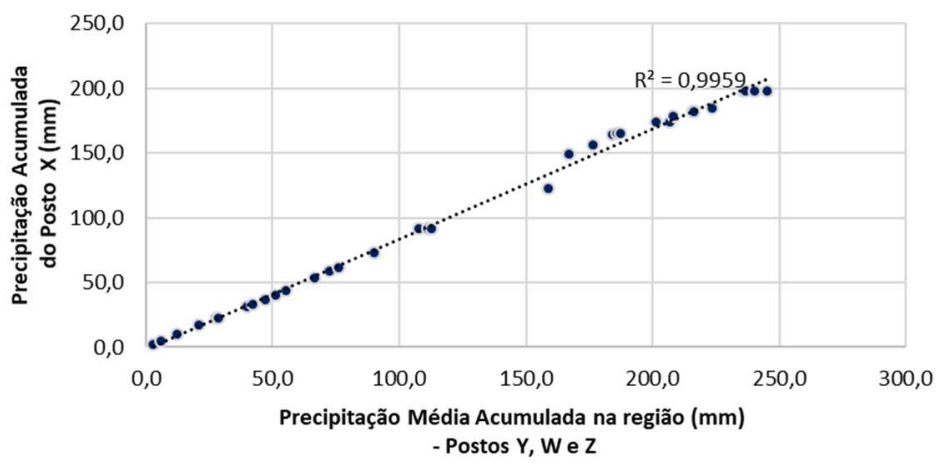

Figura 2: Exemplo do modelo Análise de Dupla Massa.

\section{RESULTADOS E DISCUSSÃO}

\section{Precipitação pluviométrica temporal anual}

O Pluviograma Anual (Figura 3) da BHRPB, se apresenta da seguinte maneira, caracterizado com 26 anos abaixo da média do período analisado que foi de $58,6 \mathrm{~mm}$, sendo o ano de 1998 considerado o menor em valores de precipitação atingindo $27 \mathrm{~mm}$. Deste modo, a caracterização da seca elevada neste ano não foi exclusiva apenas da região, e sim de todo o NEB, decorrente do El Niño muito forte nesse ano.

Para Sousa et al. (2015), o impacto causado pelo fenômeno El Niño (La Niña), dependendo da sua intensidade pode resultar em secas (enchentes) severas, interferindo de forma significativa nas atividades econômicas nas regiões Norte e Nordeste do Brasil.

Além disso a BHRPB apresentou 14 anos acima da média da pluviosidade possuindo o ano de 2011 como o pico máximo, atingindo $95 \mathrm{~mm}$. Portanto, através desse resultado nota-se uma variação na série histórica, enfatizando que em series como essa, é importante a alternância entre esses períodos, entre pouca intensidade de chuvas e uma alta concentração, neste sentido se mantem o equilíbrio.

Segundo Muthoni et al. (2019), a interpretação dos padrões espaço-temporais da variabilidade pluviométrica é o passo fundamental para criação de novos projetos, visando estratégias adaptativas 
adequadas para uma determinada localidade.

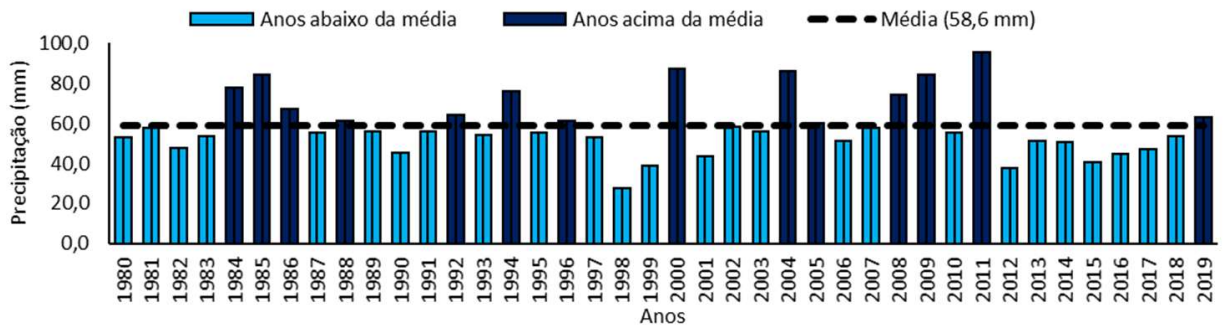

Figura 3: Pluviograma de precipitação anual da BHRPB de 1980 a 2019.

\section{Precipitação pluviométrica temporal mensal}

De acordo com a série histórica, foi possível evidenciar dois períodos distintos, com seis meses para ambos na BHRPB (Figura 4). Logo, um deles é caracterizado como chuvoso, que vai de fevereiro a julho, sendo março e abril os meses maior quantidade de chuvas, atingindo $106 \mathrm{~mm}$ e $105 \mathrm{~mm}$ respectivamente, ou seja, $47 \mathrm{~mm}$ ou $81 \%$ maior que a média histórica.

Segundo, Nóbrega et al. (2016) ocorre uma substantiva irregularidade espacial das chuvas, dentro do mesmo intervalo temporal, em virtude da atuação de sistemas meteorológicos de diferente abrangência sobre a região. Logo, esses sistemas interferem no decorrer dos meses durante todo o ano.

Por outro lado, existe o período seco, que tem início em agosto e se estende até janeiro, com destaque para os meses de outubro e setembro que atingem no máximo 9,5 mm, ou seja, 49,1 mm ou $85 \%$ menor que a média histórica. Nesses meses secos é que se destacam a importância de um bom gerenciamento dos recursos hídricos para a região, visto que por sofrerem com a estiagem requer uma atenção maior.

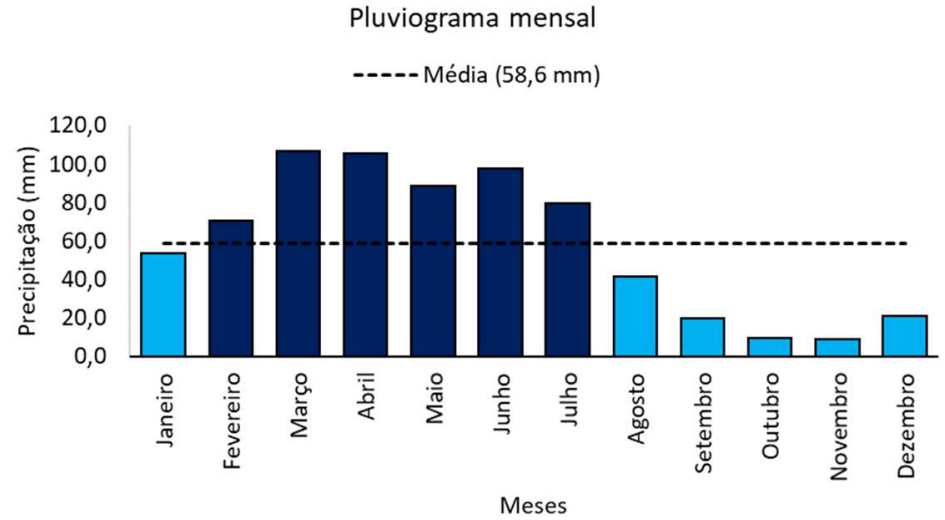

Figura 4: Pluviograma de precipitação mensal da área da BHRPB de 1980 a 2019.

Além disso, a distribuição da precipitação média da BHRPB (Figura 5), é representada por 78\% da precipitação presente no período úmido, esse fato é de extrema importância, pois o conhecimento destas informações, pode ocasionar projetos para elaboração de estratégias e ações que visem o desenvolvimento da região.

Consequentemente os $22 \%$ da pluviosidade se encontram no período seco, ou seja, seis meses no qual a quantidade hídrica na região é baixa, principalmente nas áreas mais ao oeste. Com o conhecimento dessas informações, as autoridades públicas, podem desenvolver medidas no intuito de promover a 
preservação da água nesta área, prevenindo assim que o nível de escassez durante os anos não seja tão intenso.

De acordo com Pereira et al. (2017), a seca é uma estiagem de ordem mais severa e ela acaba acarretando a redução das reservas hídricas, tendo como impacto o abastecimento de água nas áreas afetadas.

Logo, Souza et al. (2017) afirmam a importância de se aprofundar o conhecimento em relação à variabilidade interanual e sazonal da precipitação no NEB, para que sejam definidas políticas públicas voltadas para manutenção e preservação dos recursos hídricos.

$$
\text { - Período chuvoso } \quad \text { Período seco }
$$

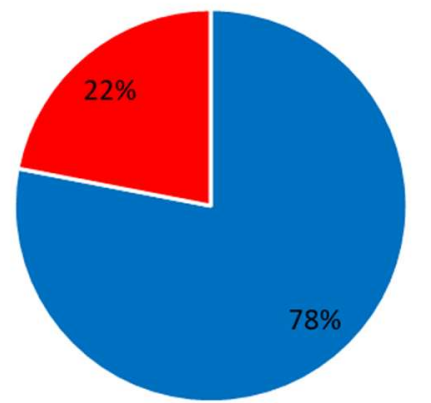

Figura 5: Percentual da precipitação da microrregião de Sousa nas estações seca e chuvosa.

\section{Precipitação pluviométrica espacial mensal}

No intuito de compreender o comportamento dinâmico da precipitação, analisou-se a espacialização da BHRPB mensalmente, figura 6 (A) a (L).

Nas Isoietas médias mensais da Precipitação da BHRPB, foram ilustradas o comportamento pluviométrico dos meses, no qual o mês de janeiro (Figura 6A) se caracteriza como o último mês seco, sendo o da transição para o período chuvoso. Logo os maiores valores foram demostrados na parte leste atingindo $125 \mathrm{~mm}$, outros pontos com intensidades mais elevadas foram demostrados na parte oeste com 90mm.

Por outro lado, os menores valores atingiram no máximo $25 \mathrm{~mm}$, sendo observados em pequenas partes ao norte, e outros pontos mais ao sul, sudeste e sudoeste. Além disso, a região central da BHRPB se demostra ser a região com menor índice de chuvas.

O mês de fevereiro (Figura 6B), é caracterizado por iniciar o período chuvoso da série estudada, para a região é considerada o mês de amenização e de um fluxo maior para os mananciais e reservatórios disponíveis, principalmente na região oeste do estudo. Assim sendo, a região apresenta os maiores valores encontrados na parte oeste e leste atingindo $116 \mathrm{~mm}$. Logo, a parte com menores quantidade de chuvas foi a região central, atingindo no mínimo $36 \mathrm{~mm}$.

Para os meses de março e abril (Figuras 6C e 6D), meses de extrema importância para a BHRPB de modo geral, visto que numa escala de Bacia a distribuição de chuvas está de forma igualitária com as menores precipitações da ordem de $50 \mathrm{~mm}$ na parte central. Logo, na parte oeste atinge $170 \mathrm{~mm}$, e no Leste $250 \mathrm{~mm}$ sendo os maiores valores distribuídos no decorrer da área estudada. 
Portanto, nesses meses se retêm uma boa quantidade de chuvas distribuídas por toda a BHRPB, o que beneficia a flora e a fauna, além das atividades humanas, ajuda na manutenção e no aumento da vazão dos reservatórios para o abastecimento público. Além disso, implica na mudança de temperatura em partes da região e favorece a produtividade na agricultura.

Segundo o INMET (2020) o litoral é o setor que apresenta os maiores índices pluviométricos da Paraíba. Portanto, fica evidenciado na figura 6 que a parte leste é onde ocorre os maiores valores de precipitação, no decorrer de todos os meses.

Para o mês de maio (Figura 6E), em sua extensão territorial da BHRPB, observa-se que que a precipitação não ultrapassa dos $80 \mathrm{~mm}$, sendo a maior parte ficando entre os $35 \mathrm{~mm}$, na região central do estudo, já a região oeste em pequenos fragmentos de área seus valores passam dos $80 \mathrm{~mm}$, e ao leste seus valores ultrapassam os $300 \mathrm{~mm}$.

Desse modo, nota-se uma distribuição de chuvas desigual na região, com intensidades de chuvas distintas, cuja variabilidade, pode ser explicada pelas chuvas ao leste estarem sofrendo a interferência das ZCIT, que ocorrem em maior intensidade nesses meses do ano até julho.

Já os meses de junho e julho (Figuras 6F e 6G), se assemelham em relação a distribuição espacial, visto que os menores valores observados na região, estão ao oeste variando entre $16 \mathrm{~mm}$ e $30 \mathrm{~mm}$. Na outra metade da BHRPB é possível evidenciar que as precipitações, principalmente próximas o litoral os valores atingem $368 \mathrm{~mm}$, e vem diminuindo gradativamente até a região central que atinge $90 \mathrm{~mm}$.

Vale enfatizar ainda, que essa distribuição favorece os mananciais mais próximos ao leste, visto que o acúmulo de chuvas se dá de maneira mais homogênea nesta região, o que garante uma estabilidade e fluxo nesses reservatórios. Deste modo, o mesmo não ocorre na região mais ao oeste, visto que essas chuvas não chegam com tanta intensidade como nos primeiros meses do ano, tal situação ocorre pelo fenômeno natural do Planalto da Borborema que serve de barreira natural, inibindo que a chuva chegue para os demais municípios ao oeste. Além disso, julho (Figura 6G), é o último mês do período chuvoso.

O início do período seco, se dá a partir de agosto (Figura $6 \mathrm{H}$ ), nota-se uma diminuição significativa em termos representativos em toda a região, caracterizando a mesma com cerca de $60 \%$ entre $5 \mathrm{~mm}$ e 20 $\mathrm{mm}$, nas regiões central e oeste. Contudo, 40 \% da região em uma pequena parte central a leste, variam de $60 \mathrm{~mm}$ a $155 \mathrm{~mm}$, ou seja, já tem uma ampla diferença dos meses anteriores caracterizados no período chuvoso.

Por fim, os meses de setembro a dezembro (Figuras 6I, 6J, 6K e 6L), é possível evidenciar que no decorrer da BHRPB, a precipitação se mante homogênea, nota-se pouca diferença de uma região para outra, os níveis de precipitação variam entre $42 \mathrm{~mm}$ no máximo (com exceção de setembro, que atinge 83 ao leste), e em sua grande maioria fica entre $5 \mathrm{~mm}$ principalmente nas regiões central e oeste.

Desse modo, é de extrema importância que nesses meses de extrema seca os gestores municipais e estadual, junto com os proprietários locais, e com o apoio da população fiquem atentos pela questão hídrica nos municípios, principalmente os da parte central na região estudada, visto que o uso d'água deve ser 
consciente e adequado ao equilíbrio ambiental.

Assim, a gestão deste recurso hídrico, deve ser realizada visando a sua oferta para todos, considerando a sua interação com outros elementos do meio e dinâmicas antrópicas relacionadas (CALADO et al., 2020).

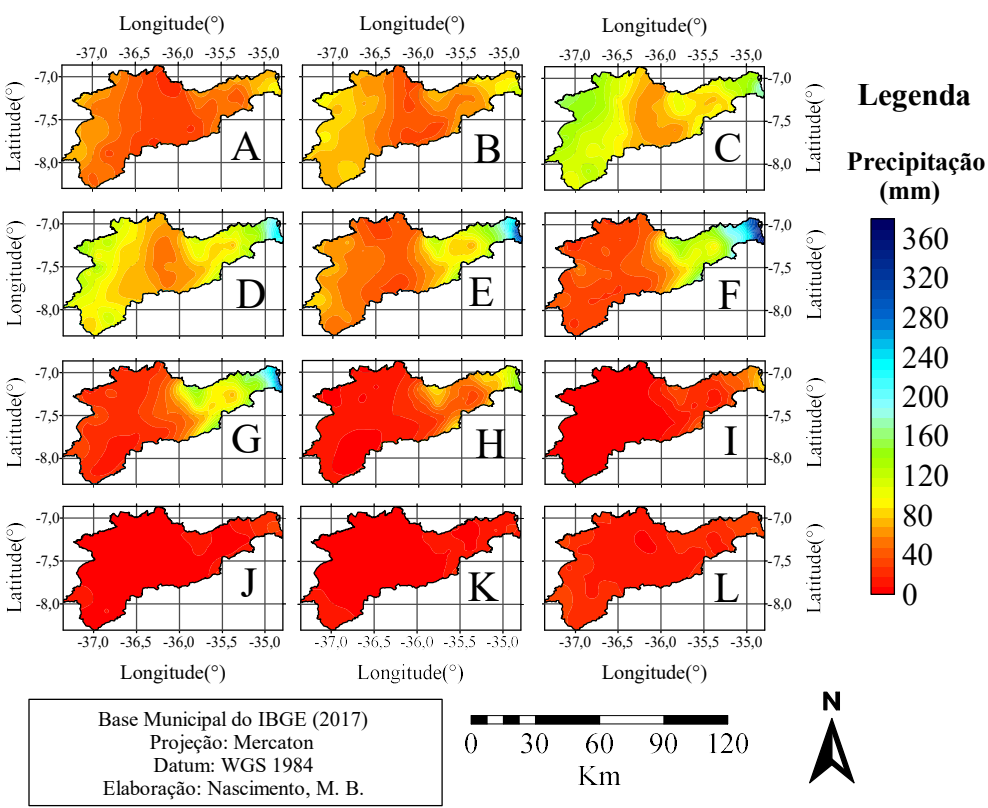

Figura 6: Isoietas médias mensais de Precipitação Pluviométrica da BHRPB de Janeiro (A), Fevereiro (B), Março (C), Abril (D), Maio (E), Junho (F), Julho (G), Agosto (H), Setembro (I), Outubro (J), Novembro (K) e Dezembro (L).

\section{CONCLUSÕES}

De acordo com os resultados obtidos pode-se destacar que no período de 1980 a 2019 a precipitação pluviométrica temporal anual apresentou 26 anos abaixo da média, destacando o ano de 1998 como o pico mínimo de 27,9 mm e 14 acima da média, sendo 2011 apresentando o valor máximo de 95,6 mm.

Em relação a análise mensal, foi possível caracterizar dois períodos distintos na BHRPB. Um período chuvoso, que compreende os meses de fevereiro a julho, sendo março e abril os mais representativos, atingindo $106 \mathrm{~mm}$ e $105 \mathrm{~mm}$ respectivamente, um período seco que tem início em agosto e se estende até janeiro, sendo os meses de outubro e setembro os que mais se destacam, atingindo o máximo de 9,5 mm.

$\mathrm{Na}$ análise espacial da precipitação, as isoietas demostram, como as chuvas estão especializadas no decorrer dos meses na BHRPB, destacando a parte leste como maiores chuvas e uma pequena parte ao oeste da bacia, em contrapartida, a região central apresenta os menores índices de intensidade de chuvas.

Por fim, através desses resultados e com o conhecimento da variável ambiental precipitação, ajudara a compreender como ela se comporta no decorrer dos meses e anos, e além disso na gestão de projetos na Bacia hidrográfica, a fim de facilitar um melhor gerenciamento dos recursos hídricos, da biodiversidade e atividades locais existente na região.

\section{REFERÊNCIAS}

ARAÚJO, L. E.; BECKER, C. T.; PONTES, A. L.. Periodicidade da precipitação pluviométrica no estado da Paraíba. In: CONGRESSO BRASILEIRO DE AGROMETEOROLOGIA, RIO
GRANDE DO SUL, 13. Anais. Santa Maria: RS, 2003. p.947948. 
ARAÚJO, L. E.; SOUSA, F. A. S.; RIBEIRO, M. A. F. M.; SANTOS, A. S.; MEDEIROS, P. C.. Análise estatística de chuvas intensas na bacia hidrográfica do Rio Paraíba. Revista Brasileira de Meteorologia, v.23, n.2, p.162-169, 2008. DOI: https://doi.org/10.1590/S0102-77862008000200005

CALADO, T. O.; MARQUES, E. A. T.; SOBRAL, M. C.. Planos diretores na articulação da gestão de recursos hídricos com o uso do solo no entorno de reservatórios. Revista Brasileira de Geografia Física, v.13, n.3, p.958-972, 2020. DOI: https://doi.org/10.26848/rbgf.v13.3.p958-972

FLATO, M.; MUTTARAK, R.; PELSER, A.. Women, Weather, and Woes: The Triangular Dynamics of Female-Headed Households, Economic Vulnerability, and Climate Variability in South Africa. World Development, v.90, n.17, p.41-62, 2017. DOI: https://doi.org/10.1016/j.worlddev.2016.08.015

FERREIRA, P. S.; SOUZA, W. M.; SILVA, J. F.. Variabilidade Espaço-Temporal das Tendências de Precipitação na Mesorregião Sul Cearense e sua Relação com as Anomalias de TSM. Revista brasileira de meteorologia, v.33, n.1, p.141152, 2018. DOI: https://doi.org/10.1590/0102-7786331006

FERREIRA, C. C.; PIMENTEL, F. O.; VIANNA, Y. C. G.. Proposta Metodológica Aplicada ao Estudo de Clima Urbano. Revista Brasileira de Geografia Física, v.12, n.6, p.2023-2040, 2019. DOI: https://doi.org/10.26848/rbgf.v12.6.p2023-2040

FRANCISCO, P. R. M.; MEDEIROS, R. M.; SANTOS, D.; MATOS, R. M.. Classificação Climática de Köppen e Thornthwaite para o Estado da Paraíba. Revista Brasileira de Geografia Física, v.8, n.4, p.1006-1016, 2015. DOI: https://doi.org/10.5935/1984-2295.20150049

INMET. Instituto Nacional de Meteorologia. Normais Climatológicas do Brasil, 1981 - 2010. Brasília: INMET, 2020.

MUTHONI, F. K.; ODONGO, V. O.; OCHIENG, J.; MUGALAVAI, E. M.; MOURICE, S. K.; ZELEDON, I. H.; MWILA, M.; BEKUNDA, M.. Long-term spatial-temporal trends and variability of rainfall over Eastern and Southern Africa. Theoretical and Applied Climatology, v.137, n.3-4, p.18691882, 2019. DOI: https://doi.org/10.1007/s00704-018-27121
NASCIMENTO, M. B.; BANDEIRA, M. M.; ARAÚJO, L. E.. Variabilidade climática da precipitação do município de Areia/Paraíba, Brasil. Gaia Scientia, v.13, n.3, p.24-37, 2019.

NÓBREGA, R. S.; SANTIAGO, G. A. C. F.; SOARES, D. B.. Tendências do controle climático Oceânico sob a variabilidade temporal da precipitação no Nordeste do Brasil. Revista Brasileira de Climatologia, v.18, p.276-292, 2016. DOI: http://dx.doi.org/10.5380/abclima.v18i0.43657

OLIVEIRA, R. M. M.; SANTOS, E. V.; LIMA, K. C.. Avaliação da qualidade da água do riacho São Caetano, de Balsas (MA), com base em parâmetros físicos, químicos e microbiológicos. Revista Engenharia Sanitária e Ambiental, v.22, n.3, p.523-530, 2017. DOI:

https://doi.org/10.1590/s1413-41522017154657

PALHARINI, R. S. A.; VILA, A. D.. Climatological Behavior Precipitating Clouds in the Northeast Regions of Brazil. Advances in Meteorology, p.1-12, 2017. DOI: https://doi.org/10.1155/2017/5916150

PEREIRA, M. L. T.; SOARES, M. P. A.; SILVA, E. A.; MONTENEGRO, A. A. A.; SOUZA, W. M.. Variabilidade climática no Agreste de Pernambuco e os desastres decorrentes dos extremos climáticos. Journal of Environmental Analysis and Progress, v.2, n.4, p.394-402, 2017. DOI:

https://doi.org/10.24221/jeap.2.4.2017.1452.394-402

SIQUEIRA, B.; NERY, J. T.. Análise do Índice Padronizado de Precipitação para o Estado de São Paulo. Revista Brasileira de Geografia Física, v.10, n.6, p.1775-1783, 2017. DOI: https://doi.org/10.26848/rbgf.v10.6.p1775-1783

SOUSA, A. M. L.; ROCHA, E. J. P.; VITORINO, M. I.; SOUZA, P. J. O. P.; BOTELHO, M. N.. Variabilidade espaco-temporal da precipitação na Amazônia durante eventos ENOS. Revista Brasileira de Geografia Física, v.8, n.1, p.13-24, 2015. DOI: https://doi.org/10.26848/rbgf.v8.1.p013-024

SOUZA, C. L. O.; NOGUEIRA, V. F. B.; NOGUEIRA, V. S.. Variabilidade interanual da precipitação em cidades do semiárido brasileiro entre os anos de 1984 e 2015. Revista Verde de Agroecologia e Desenvolvimento Sustentável, v.12, n.4, p.740-747, 2017. DOI: https://doi.org/10.18378/rvads.v12i4.5626

A CBPC - Companhia Brasileira de Produção Científica (CNPJ: 11.221.422/0001-03) detém os direitos materiais desta publicação. Os direitos referem-se à publicação do trabalho em qualquer parte do mundo, incluindo os direitos às renovações, expansões e disseminações da contribuição, bem como outros direitos subsidiários. Todos os trabalhos publicados eletronicamente poderão posteriormente ser publicados em coletâneas impressas sob coordenação da Sustenere Publishing, da Companhia Brasileira de Produção Científica e seus parceiros autorizados. Os (as) autores (as) posteriormente ser publicados em coletâneas impressas sob coordenação da Sustenere Publishing, da Companhia Brasileira de Produção Cientifica e seus parce
preservam os direitos autorais, mas não têm permissão para a publicação da contribuição em outro meio, impresso ou digital, em português ou em tradução. 